\title{
REVIEW
}

\section{THE BEST INFERTILITY TREATMENT FOR VASECTOMIZED MEN: ASSISTED REPRODUCTION OR VASECTOMY REVERSAL?}

Fábio Firmbach Pasqualotto, Antônio Marmo Lucon, Bernardo Passos Sobreiro, Eleonora Bedin Pasqualotto and Sami Arap

PASQUALOTTO FF et al. The best infertility treatment for vasectomized men: assisted reproduction or vasectomy reversal?

Rev. Hosp. Clín. Fac. Med. S. Paulo 59(5):312-315, 2004.

In men with prior vasectomy, microsurgical reconstruction of the reproductive tract is more cost-effective than sperm retrieval with in vitro fertilization and intracytoplasmic sperm injection if the obstructive interval is less than 15 years and no female fertility risk factors are present. If epididymal obstruction is detected or advanced female age is present, the decision to use either microsurgical reconstruction or sperm retrieval with in vitro fertilization and intracytoplasmic sperm injection should be individualized.

Sperm retrieval with in vitro fertilization and intracytoplasmic sperm injection is preferred to surgical treatment when female factors requiring in vitro fertilization are present or when the chance for success with sperm retrieval and intracytoplasmic sperm injection exceeds the chance for success with surgical treatment.

\section{KEY WORDS: Semen. Vasectomy. Reversal. Reproduction. Fertilization. Infertility.}

Although obstructive azoospermia accounts for only a small percentage of male infertility, it is the diagnosis that has attracted significant attention in the cost-effectiveness scenario. ${ }^{1}$ This attention is attributable to the fact that vasectomy is the most common form of obstruction encountered in the treatment of infertility. ${ }^{2,3}$ Vasectomy reversal is requested by $2 \%$ to $6 \%$ of men to restore their fertility. ${ }^{3-5}$ Furthermore, vasectomy reversal has been deemed an effective modality that has been widely embraced by the urologic community. ${ }^{4-11}$

Until recently, the only treatment available for restoring fertility after vasectomy was reconstruction. ${ }^{4,6}$ Treatment for patients with seminal tract obstruction is either microsurgical repair of the obstruction or sperm retrieval and in vitro fertilization (IVF) with intracytoplasmic sperm injection (ICSI). ${ }^{12-15}$ Surgical correction may be accomplished by microsurgical reconstruction of the vas and /or epididymis, but prior to performing the microsurgery, the female partner should be evaluated to determine if female infertility factors are present. ${ }^{16}$ In addition, microsurgical procedures have been shown to be more cost-effective than sperm retrieval with IVF or ICSI, which requires intervention in both the

From the Department of Urology, Hospital das Clínicas, Faculty of Medicine, University of São Paulo - São Paulo/SP, Brazil and Department of Biomedical Sciences, University of Caxias do Sul - Caxias do Sul/ RS, Brazil.

E-mail: fabio@conception-rs.com.br Received for publication on February 27, 2004. male and female partners. ${ }^{7,8,11,17}$ Of utmost importance, microsurgical reconstruction, if successful, allows couples to have more children without medical treatment. ${ }^{5}$ Therefore, in most cases, microsurgical reconstruction is more appropriate as an initial treatment for obstructive azoospermia. ${ }^{5} \mathrm{Al}-$ though there are many technical difficulties that may result in immediate or late technical failures, vasovasostomy results in restoration of sperm in the ejaculate (patency) in approximately $90 \%$ of patients. ${ }^{5,6,10,16,17}$ Pregnancy rates of $44 \%$ to $60 \%$ and delivery rates of $36 \%$ to $47 \%$ have been reported. $5,6,10,16,17$

A very important factor influencing the likelihood of sperm returning to the semen and of pregnancy after vasectomy reversal is the number of 
years between vasectomy and attempted reconstruction. ${ }^{5}$ The length of obstruction interval and the chance for successful outcome of vasectomy reversal are inversely related. Other factors influencing the success of vasectomy reversal include: the presence or absence of sperm in the intraoperative vas fluid, the gross appearance of the vas fluid, the quality of the sperm in the vas fluid, the length of the vas segment between the epididymis and the vasectomy site, the presence or absence of a sperm granuloma at the vasectomy site, and female age. ${ }^{5}$

Vasoepididymostomy (VE) is thought to be one of the more difficult microsurgical procedures performed by urologists. ${ }^{6,11}$ Its success rate has improved markedly with the development of specific tubule end-to-end and end-to-side microsurgical anastomoses. The reported success rates for vasoepididymostomy are considerably lower than those reported for vasovasostomy. ${ }^{5,6,11}$ The patency rates for VE range from $70 \%$ to $85 \%$, and pregnancy rates range from $31 \%$ to $56 \%$ in the treatment of men with epididymal obstruction from all causes. ${ }^{6,11}$ The best results are achieved by surgeons with training and ongoing experience in microsurgery.

However, there are situations where sperm retrieval with IVF/ICSI may be the method of choice for couples in which the male has obstructive azoospermia. The success and widespread availability of IVF/ICSI has resulted in controversy regarding the most effective management of this condition. ${ }^{12-15,18-20}$

Intracytoplasmic sperm injection is an adjunct to standard IVF and must be used in almost all cases in which sperm are retrieved from the testes or epididymis of a man with obstructive azoospermia, because the sperm retrieval techniques very rarely produce enough motile sperm for intrauterine insemination (IUI) or standard IVF. ${ }^{20}$
Intracytoplasmic sperm injection provides fertilization rates of $45 \%$ to $75 \%$ per injected oocyte when surgically retrieved epididymal or testicular spermatozoa are used. ${ }^{14,19,20}$ Clinical pregnancy rates range from $26 \%$ to $57 \%$, and delivery rates range from $18 \%$ to $54 \% .^{14,19,20}$ It is important to note here that sperm retrieval is best performed by a surgeon trained in this procedure because of the possible postoperative complications of sperm retrieval. ${ }^{19}$ These complications include bleeding and infection that may require surgical intervention. ${ }^{19}$

The most common methods of sperm retrieval are microsurgical epididymal sperm aspiration (MESA), percutaneous epididymal sperm aspiration (PESA), testicular sperm extraction (TESE), and percutaneous testicular sperm aspiration (TESA). ${ }^{13-15,19}$ The choice of sperm retrieval method depends primarily on the experience and preference of both the physician who will perform the retrieval and the IVF laboratory embryologist. ${ }^{19}$ There are not enough data to conclude that choice of either the technique of sperm retrieval (open or percutaneous) or the source of the sperm (testicular, epididymal, vassal, or seminal vesicular) significantly affects pregnancy rates. In a recent study, no differences were seen in the fertilization rates and embryo transfer with respect to the etiology (obstructive vs. nonobstructive) and type of spermatozoa (epididymal vs. testicular). ${ }^{20}$ However, retrieved testicular sperm results in lower fertilization and pregnancy rates as well as higher abortion rates compared to retrieved epididymal sperm. ${ }^{20}$

Any couple considering IVF/ICSI should be apprised of the risks involving this type of treatment. ${ }^{21-25}$ These risks include the possibility of ovarian hyperstimulation, the potential complications of oocyte retrieval, and the risks and consequences of multiple gestations. ${ }^{21}$ In vitro fertilization car- ries an incidence of ovarian hyperstimulation syndrome in up to $20 \%$ of patients, being moderate in up to $5 \%$ and severe requiring hospitalization in $1 \% .^{21}$ The risk of multiple gestation is $20 \%$ to $35 \%$ for twin gestations and $5 \%$ to $10 \%$ for triplets or higher-order gestations..$^{22-25}$ Multiple gestations are associated with increased infant morbidity and mortality rates due to prematurity. ${ }^{22-25}$

Female infertility factors might also favor the selection of IVF/ICSI. The fertility status of the female partner is related to age, the presence or absence of specific risk factors such as endometriosis, or ovulatory dysfunction. ${ }^{5,16}$ When the female partner has tubal disease or has undergone tubal ligation, sperm retrieval with IVF/ICSI is clearly preferable because it avoids subjecting both partners to reconstructive microsurgery. ${ }^{16}$

The woman's age is important because a woman's fertility progressively decreases after age 35 years and is limited after 40 years. ${ }^{10-16}$ In addition, it has recently been shown that the age affects semen quality. ${ }^{26}$ Due to the fact that the average interval until pregnancy after successful microsurgical vasectomy reversal is 12 months, couples may consider sperm retrieval with ICSI when the female partner is older than 37 years of age. However, in couples in which the female partner is approaching the age 40 , the success rate of IVF with or without ICSI decreases dramatically. It was shown recently that it is worthwhile to perform a microsurgical reconstruction of the male tract even in cases when the female is older than 35 years. Older women should be evaluated before any fertility treatment is undertaken. The choice of either sperm retrieval with IVF/ICSI or microsurgical reconstruction should also be influenced by the pregnancy rates achieved with ICSI by the IVF team when epididymal or testicular sperm is used and by the sur- 
geon's results with microsurgical reconstructive procedures. ${ }^{10,16}$

Pavlovich and Schlegel conducted a cost analysis utilizing published data comparing reconstruction and IVF with sperm acquisition. ${ }^{9}$ Assuming a pregnancy rate of $47 \%$ after an initial attempt at vasectomy reversal, these authors demonstrated a cost per delivery of US $\$ 25,475$. The delivery rate after 1 cycle of sperm retrieval and ICSI was 33\%. These later techniques were associated with a cost per delivery of $\$ 72,521$, with an average of $\$ 71,896$ for percutaneous testicular sperm retrieval and $\$ 73,146$ for surgical sperm retrieval.

When there is an obstruction in the epididymis following the vasectomy procedure, it is also amenable to microsurgical reconstruction. ${ }^{11}$ Kolettis and Thomas showed that the cost per delivery for vasoepididymostomy was $\$ 31,099$ compared to $\$ 51,024$ for ICSI, assuming $36 \%$ and $29 \%$ delivery rates, respectively.

Unfortunately, not all patients conceive after microsurgical reconstruction or IVF with ICSI. Patients must elect to undergo a second attempt at reconstruction or explore assisted reproductive options if the primary attempt was unsuccessful. ${ }^{6,27}$ Since many patients may not be willing to undergo another surgical intervention, it is recommended that patients must be aware of the possibility of sperm cryopreservation at the time of attempted reconstruction. ${ }^{28,29}$ Patients undergoing IVF/ICSI as their primary therapy may also cryopreserve sperm at the time of their initial acquisition. ${ }^{28,29}$

Clearly, the cost per delivery for reconstruction in cases of obstructive azoospermia is less than that associated with IVF/ICSI. ${ }^{911}$ This information must be used in the decision algorithm for the couples wishing fertility after vasectomy. The final decision regarding microsurgical reconstruction or sperm retrieval with IVF/ICSI is ideally made by the well-informed couple together with their reproductive specialist.

\section{RESUMO}

PASQUALOTTO FF e col. Melhor tratamento da infertilidade no homem vasectomizado: reprodução assistida ou reversão de vasectomia? Rev. Hosp. Clín. Fac. Med. S. Paulo 59(5):312-315, 2004.

Reconstrução microcirúrgica do trato reprodutivo é preferível à captação de espermatozóides com Fertilização in vitro e Injeção intracitoplasmática de espermatozóides em homens vasectomizados quando o intervalo de obstrução for inferior a 15 anos e au- sência de fatores de risco para infertilidade feminina. Se ocorrer uma obstrução epididimária ou se a mulher possuir uma idade avançada, a decisão para ou reconstrução microcirúrgica ou captação de espermatozóides com fertilização in vitro ou Injeção intracitoplasmática de espermatozóides deve ser individualizada.

Captação espermática com fertilização in vitro e Injeção intracitoplasmática de espermatozóides é preferível ao tratamento cirúrgico quando o tratamento do fator feminino re- quer fertilização in vitro ou quando a chance de sucesso com a captação de espermatozóides e Injeção intracitoplasmática de espermatozóides são superiores às chances de sucesso com a captação de espermatozóides e Injeção intracitoplasmática de espermatozóides são superiores às chances com o tratamento cirúrgico.

UNITERMOS: Sêmen. Vasectomia. Reversão. Reprodução. Fertilização. Infertilidade.

\section{REFERENCES}

1. Jarow JP, Espeland MA, Lipshultz LI. Evaluation of the azoospermic patient. J Urol 1989;142:62-5.

2. Raleigh VS. Trends in world population: how will the millenium compare with the past? Hum Reprod Update 1999;5:500-5.

3. Potts JA, Pasqualotto FF, Nelson D, Agarwal A, Thomas AJ Jr. Patient characteristics associated with vasectomy reversal. J Urol 1999;161:1835-9.

4. Sandlow JI, Westefeld JS, Maples MR, Scheel KR. Psychological correlates of vasectomy. Fertil Steril 2001;75:544-8.
5. Belker AM, Thomas AJ Jr, Fuchs EF, Konnak JW, Sharlip ID. Results of 1,469 microsurgical vasectomy reversals by the vasovasostomy group. J Urol 1991;145:505-11.

6. Pasqualotto FF, Agarwal A, Srivastava M, Nelson D, Thomas AJ Jr. Fertility outcome after repeat vasoepididymostomy. J Urol 1999;162:1626-8.

7. Comhaire F. Economic strategies in modern male subfertility treatment. Hum Reprod 1995; 10(1): 103-106.

8. Russell LB, Gold MR, Siegel JE, Daniels N, Weinstein MC. The role of cost-effectiveness analysis in health and medicine. JAMA 1996;276:1172-7. 
9. Pavlovich CP, Schlegel PN. Fertility options after vasectomy: A cost-effectiveness analysis. Fertil Steril 1997;67:133-41.

10. Kolettis PN, Sabanegh ES, Nalesnik JG, D'Amico AM, Box LC, Burns JR. Pregnancy outcomes after vasectomy reversal for female partners 35 years old or older. J Urol 2003;169:22502 .

11. Kolettis PN, Thomas AJ Jr. Vasoepididymostomy for vasectomy reversal: a critical assessment in the era of intracytoplasmic sperm injection. J Urol 1997;158:467-70.

12. Palermo GD, Schlegel PN, Hariprashad JJ, Ergun B, Mielnik A, Zaninovic N, et al. Fertilization and pregnancy outcome with intracytoplasmic sperm injection for azoospermic men. Hum Reprod 1999;14:741-8.

13. Silber SJ, Nagy ZP, Liu J, Godoy H, Devroey P, Van Steirteghem AC. Conventional in vitro fertilization versus intracytoplasmic sperm injection for patients requiring microsurgical sperm aspiration. Hum Reprod 1994;9:1705-9.

14. Borges E Jr, Rossi-Ferragut LM, Pasqualotto FF, Rocha CC, Iaconelli Junior A. Is there a difference between different intervals after vasectomy and the reproductive capacity for vasectomized men? J Assist Reprod Genet 2003;20:33-7.

15. Schlegel PN, Palermo GD, Alikani M, Adler A, Reing AM, Cohen J, et al. Micropuncture retrieval of epididymal sperm with IVF: importance of in vitro micromanipulation techniques. Urol 1995;46:238-41.

16. Deck AJ, Berger RE. Should vasectomy reversal be performed in men with older female partners? J Urol 2000;163:105-6.

17. Fuchs EF, Burt R. Vasectomy reversal performed 15 years or more after vasectomy: correlation of pregnancy outcome with partner age and with pregnancy results of in vitro fertilization with intracytoplasmic sperm injection. Fertil Steril 2002;77: $516-9$.

18. Osmanagaoglu K, Vernaeve V, Kolibianakis E, Tournaye H, Camus M, Van Steirteghem A, et al. Cumulative delivery rates after ICSI treatment cycles with freshly retrieved testicular sperm: a 7-year follow-up study. Hum Reprod 2003;18(9):1836-40.

19. Pasqualotto FF, Rossi-Ferragut, Rocha CC, Iaconelli A Jr, Ortiz V, Borges E Jr. Sperm retrieval and fertilization in repeated percutaneous epididymal sperm aspiration. J Urol 2003;169:1779-81.
20. Pasqualotto FF, Rossi-Ferragut LM, Rocha CC, Iaconelli A Jr, Borges E Jr. Outcome of in vitro fertilization and intracytoplasmic injection of epididymal and testicular sperm obtained from patients with obstructive and nonobstructive azoospermia. J Urol 2002;167:1753-6.

21. Bassil S, Godin PA, Stallaert S, Vercruyssen M, Demylle D, Donnez J. Ovarian hyperstimulation syndrome. A review. Assist Reprod Rev 1995;5:90-6.

22. Wilcox LS, Kiely JL, Melvin CL, Martin MC. Assisted reproductive technologies: estimates of their contribution to multiple births and newborn hospital days in the United States. Fertil Steril $1996 ; 65: 361-6$

23. Callahan TL, Hall JE, Ettner SL, Christiansen CL, Greene MF, Crowley WF Jr. The economic impact of multiple gestation pregnancies and the contribution of assisted reproduction techniques to their incidence. New Engl J Med 1994;331:2449 .

24. Osmanagaoglu K, Tournaye H, Camus M, Vandervorst M, Van Steirteghem A, Devroey P. Cumulative delivery rates after intracytoplasmic sperm injection: 5 year follow-up of 498 patients. Hum Reprod 1999;14:2651-5.

25. Osmanagaoglu K, Tournaye H, Kolibianakis E, Camus M, Van Steirteghem A, Devroey P. Cumulative delivery rates after ICSI in women aged >37 years. Hum Reprod 2002;17:940-4.

26. Pasqualotto FF, Hallak J, Lucon AM, Sobreiro BP, Peng BC, Pieri P. Effect of age on hormone levels, semen characteristics, and testicular volume. J Urol 2003; 169(4):S, 451.

27. Pasqualotto FF, Pasqualotto EB, Agarwal A, Thomas AJ Jr. Results of microsurgical anastomosis in men with seminal tract obstruction due to inguinal herniorrhaphy. Rev Hosp Clin Fac Med S Paulo 2003;58(6):305-9.

28. Belker AM, Bergamini D. The feasibility of cryopreservation of sperm harvested intraoperatively during vasectomy reversals. J Urol 1997;157:1292-4.

29. Schrepferman CG, Carson MR, Sparks AET, Sandlow JI. Need for sperm cryopreservation at vasectomy reversal. J Urol 2001;166:1787-9. 